\title{
THE EVOLVED SURVIVAL OF SM ENTERTAINMENT IN THE CHINESE MARKET Legitimation Strategies and Organizational Survival'
}

\author{
Weibo Ye \\ Marketing Communication Department, Allive Creative \\ yeweibo901@hotmail.com
}

\section{Sou Hwan Kang* \\ Department of Sociology, Korea University toroncine@korea.ac.kr}

\begin{abstract}
AVEX, a Japanese leading entertainment company, decided to withdraw from the Chinese market in 2013 due to its business failure. In contrast, SM Entertainment adapted to the Chinese market and has survived. Organizations are affected by their external environment and implement strategies to adapt and respond to this environment. This study investigates reasons for SM Entertainment's successful entry into China. We analyze how the corporation's strategies evolved to acclimatize to changes in the Chinese cultural industry policy from 1998 to 2014, and explored the results of these strategies. From this analysis, we argue that it is important for organizations to tailor their response strategies to changing external environments in order to acquire social support.
\end{abstract}

\section{Keywords}

Chinese cultural industry policy, Hallyu, legitimation strategies, SM Entertainment, sociological institutionalism

\section{About the Authors}

Weibo Ye works in the marketing communication department at Allive Creative. She holds a Bachelor from Guangdong University of Foreign Studies, and a Master of Sociology from Korea University. Her research interests include Chinese cultural and sports industry policies and international market entry strategies.

Sou Hwan Kang is a PhD candidate in the Department of Sociology at Korea University. He received his Bachelor and Master in Sociology from Korea University. His research interests include cultural industries, economic sociology, and institutional change.

* Corresponding Author 


\section{INTRODUCTION}

The old saying, "When in Rome, do as the Romans do," can be applied to companies entering foreign countries. All countries have laws, rules, and institutions, and overseas companies must learn about these systems. McDonald's, for example, has localized menus created by "McDonaldizing" traditional food from all around the world. There is the McNürn burger with authentic German Nürnberg sausage, Le Croquet McDo with French croquet-monsieur, the Turkish kebab-style McTurco, the McCurry Pan made with Indian curry and vegetables, and the McPork, which combines Japanese-style pork and teriyaki sauce. The case of McDonald's varied cuisine demonstrates one method of how to expand a market through careful approaches to local eating habits and cultures.

In contrast, when Kellogg's entered the Indian market in 1994, they initially advertised Indian breakfasts as unhealthy as a way to draw attention to Kellogg's products. With this campaign, rather than blending into the mosaic of other cultures, they came into conflict through an ad that disturbed many Indian homemakers. Moreover, Indians did not tend to drink cold milk and were turned off by Kellogg's products. Kellogg's initial entry into the Indian market ended up failing. However, after that failure, the company made Basmati rice flakes and mango-flavored cereal to follow local tastes. This strategy led to a tremendous upsurge in sales of Kellogg's products because it involved products familiar to Indians. These examples illustrate how companies adapt to new social environments, and depict how an organization's success and survival are not solely determined by the market environment. These principles can also be observed through Hallyu (Korean wave)-related companies' performance overseas.

The Hallyu phenomenon has lasted for twenty years, overturning negative predictions of its early imminent demise. With increasing scholarly interest on Hallyu-related phenomena, relevant research areas have diversified so much in so little time that Hallyu is now recognized as a multidisciplinary research field in its own right. Studies on the success factors and competitiveness of Hallyu (e.g. Cho and Sim; Oh and Park; Park) have analyzed the characteristics of strategies and content related to production process systems. Research on the economic effects of Hallyu (e.g. Kim and Ahn; Lee et al.) has analyzed the effects of exports, service balance, and copyright protection. It is clear that the field of Hallyu research has grown to encompass various interests. However, these studies are limited in their ability to explain the relationship between foreign companies and local policies.

Extant Hallyu research has two key limitations. First, studies have not considered the occurrence of conflicts between different institutional logic systems. Since Hallyu involves the global consumption of Korean pop culture products, Korean 
characteristics flow into other institutional environments. The new external existence of the products requires them to come into conflict with the new social order. Whether these conflicts are controlled or alleviated determines the acceptance of organizations and commodities by a society. Therefore, research on how to control and manage possible institutional conflicts is needed. Moreover, the influences of government policies, laws, and cultures and the responses of organizations must be considered (Khanna and Palepu; Ramamurti and Singh).

The second limitation of current Hallyu research relates to the omission of the survival processes of cultural product producers entering overseas markets. This omission stems from an approach whereby Hallyu can exist through the state-led manufacturing-oriented export model of the developmental state and whereby entertainment companies are treated as sub-partners of cultural industrialization (Won). In such a perspective, Hallyu is only a policy product of the Korean government (Walsh). However, if all of the Hallyu phenomena are put into such a research framework of the state-dominated system, the active movements of the enterprises that produce cultural products are underestimated. As a result, it is necessary to confirm the survival strategies and the business results of cultural product production companies beyond the viewpoint that Hallyu is led via national management.

In order to address these two limitations, the present study analyzes the survival of organizations, focusing on the relationship between corporate organizations and their environments. For this analysis, this article considers the characteristics of external environments, organizational responses, and the results of strategies. We look at the survival of Korean entertainment companies that have entered the Chinese market and identify the possible causes of such survival. The reason why we are focusing on the Chinese market among other overseas markets is that SM Entertainment is still thriving and spreading Hallyu products despite the difficulties for foreign companies of entering the Chinese market.

Foreign companies face three main difficulties in entering the Chinese market. First, there is not enough information to judge the situation in the Chinese market. Foreign companies are currently under pressure from the Chinese government to regulate foreign investment, and the ambiguity of Chinese policies creates difficulties in predicting policy directions and their outcomes. Second, China has strict control over the fields and content considered threats to the socialist political system. Third, there is difficulty in securing the initiative in the case of local investment or joint ventures in China. It is inevitable that dependence on Chinese partners will increase due to the many restrictions imposed by the Chinese government. 
One case delineates such difficulties. In 1998, Japanese entertainment company AVEX established a branch office in Taiwan and trained singers to enter the Chinese market. In the early days of entry, there was little competition of entertainment companies in the Chinese market, and the company's penetration into the market was successful. AVEX established a branch office in Hong Kong in 2000 and established AVEX China in Beijing in 2006. However, as time passed, AVEX singers proved unable to garner attention in the Chinese market, and their business failed, leaving behind only large debts. Eventually, in 2013, AVEX China decided to withdraw from the market.

On the other hand, SM Entertainment entered the Chinese market in 1998 and established a Chinese subsidiary in 2004 and a joint venture in 2007, raising its awareness profile in the Chinese market and steadily increasing its market sales. What allowed SM Entertainment to adapt successfully to the Chinese market? In response to this question, we analyzed the response strategies of SM Entertainment with the changes and influences of Chinese cultural industry policy. Since China implemented reforms and an open policy, the characteristics and directions of announced Chinese cultural industry policies designed to develop the Chinese cultural industry have changed. In the course of each policy change, the strategies of SM Entertainment also evolved to adapt to the external environment. Using longitudinal in-depth case study methodology based on sociological institutionalism, the present paper examines Chinese cultural industry policies from 1998 (the beginning of SM Entertainment's entry into China) to 2014, noting how SM Entertainment was affected in each period.

\section{LITERATURE REVIEW}

\section{Overseas Expansion of Cultural Production Organizations}

Proving wrong early predictions that it would merely be a temporary fad, Hallyu has become a global trend. One argument is that the existence of the Hallyu phenomenon is a result of a blend of cultural product export strategies in the private sector and cultural industry promotion policies by the national state (Kim). This means that Hallyu's sustainability is based on economic exports of cultural products through private companies and national support to raise the national image through Hallyu. This argument is based on the assumption that cultural industrial policies exist under the lead of the state and that entertainment companies are sub-partners of the government. However, to treat Hallyu as a mere policy product of the Korean government is to ignore the activities of organizations 
that produce and sell representative Korean cultural products entering overseas markets, such as K-pop idol groups.

We aim to explore the contents and results of strategies used by cultural production organizations to survive in foreign countries. Corporate organizations are embedded in society. In this sense, the contents and directions of management strategies are closely related to the environment in which the firm is located (Dess and Beard; Miller and Friesen). The strategies of responding to the characteristics of the external environment are provided for survival and growth, and the growth and survival of a company is determined by how well the strategies fit into the company's external environment. Particularly, in the case of foreign companies, it is necessary for companies to devote attention to environment-friendly strategy settings because they encompass numerous unfamiliar laws, societies, and cultural environments (Oetzel, Getz and Ladek).

Scholars have already explored SM Entertainment's strategies for overseas expansion (e.g. Kim; Jang; Park; Lee). These studies examined the organizational star formation system and organization leaders' opinions, and concluded that the characteristics of singers, overseas market structures, and distribution structures were the factors for success of entertainment companies. Park further suggested that SM Entertainment's use of global resources in terms of manufacturing creativity facilitated the international diffusion of local products.

These previous studies emphasized the perception and movement of local consumers through corporate strategies rather than institutional dimensions in overseas markets. They emphasized the understanding of local consumers and the level of knowledge specific to the local culture as success factors (Cui and Liu) in international markets. Therefore, such research is limited to short-term localization strategies to overcome cultural discounts in foreign heterogeneous environments. Most important, however, is how organizations respond to changes in external institutional environments (Kostova and Dacin).

It can be seen from many studies that organizations are disadvantaged if they are not supported by society, resulting in legitimacy losses. ${ }^{2}$ In other words, organizational legitimacy, which represents social acceptance, is considered an important resource for organizational survival (Pfeffer and Salancik; Deephouse and Suchman). Companies that are supported by a positive image from society are more likely to be embedded in the institutional environment ( $\mathrm{Li}$ and Kozhikode). 


\section{A Change in Legitimation Strategies}

Generally, institutions are defined as a set of values, norms, and procedures that affect the establishment and operation of a firm (Meyer and Rowan) or rules of the game that a majority agree and settle on (Li and Kozhikode; Peng et al.). This system constrains behavior in a wide range of areas, from individual interactions to interfirm exchange relations, and gives meaning and criteria to social behavior through norms and cognitive structures. Organizations are also influenced by changes in the institutional environment, and the justification in response to these changes secures organization stability (Meyer and Rowan; DiMaggio and Powell; Tolbert and Zucker). Therefore, paths for organizational management are directed toward justifying methods of operating resources based on the norms and traditions inherent in a society (Oliver).

However, even in the same institutional setting, there are successful companies and those that fail (Greenwood and Hinings). Each organization has its own particular situation and receives different levels of institutional pressure. Moreover, the organization's success is determined not only by how it adapts to the institutional environment, but also by its ability to use environment strategically and appropriately. Organizations that can actively change and adapt to institutional pressures can increase their chances of survival. It is important to recognize that organizations respond to changes in the external environment (Zald and Denton), and not only to institutional conformity (Meyer and Rowan; DiMaggio and Powell).

Organizations do not merely conform to the institutional environment but also create, transform, diffuse, and reproduce the institutional environment. The present paper attempts to specify how the organizations respond positively to changes in the external environment through the concept of legitimation strategies. The legitimation strategies show us that the directions of strategies can differ depending on each external environment organization. During institutionalization, not everyone is affected by the same content or responds to external shocks in the same way. Possible strategies exist based on situational conditions (Suchman).

Strategies for responding to changes in the external environment can be broadly divided into five categories: acquiescence, compromise, avoidance, defiance, and manipulation. "Acquiescence" appears when organizations cannot be free from external sanctions and evaluations of the external environment. "Compromise" is a call for relaxation of regulation by negotiating with stakeholders, partly in accepting regulations. "Avoidance" is the act of hiding behavior, providing a buffer through decoupling, or fleeing to other market environments, in order to temporarily avoid the pressure of existing institutions. "Defiance" is the neglect of, challenge of, and attack on existing norms and institutions, when existing norms and institutions 
are ambiguous and not clear of norms or external expectations. "Manipulation" involves capturing the people who impose external pressure on organizations and spreading organizational values and norms (Oliver).

We focused on how each of these strategy types was utilized to explain why SM Entertainment was able to adapt to the Chinese market. In particular, we examined changes in the resources and strategies of SM Entertainment in Chinese cultural industry policy. For this purpose, we employed longitudinal in-depth case study methods to analyze Chinese culture industry policy and the types and results of SM Entertainment's strategy to cope with changes.

\section{Why We Analyzed SM Entertainment}

We focused our analytic lens on SM Entertainment for two primary reasons. One is that the company has its own unique production system, and the other is that SM Entertainment has successfully advanced overseas through this system. These two facts are the appropriate conditions to ascertain the role of SM Entertainment's unique organizational management strategies in mitigating institutional conflicts in the new external environment. The conditions also allowed us to identify strategies used by SM Entertainment to disseminate its values in order to gain social support from the new social environment, meaning the company is suitable for embedding into an unfamiliar, foreign society. It is a good case to illustrate the process for overcoming legitimate challenges from a new external environment.

SM Entertainment has systemized, specialized, and divided up its organizational processes to create a unique production system of celebrities. Since 1995, the company has endeavored to systematize and separate the entertainers' casting, training, and marketing processes. ${ }^{3}$ Separate departments operate systematically, including a casting team, a training team, a production director team to produce concepts and visual images of artists, an artists and repertoire (A\&R) team to manage the music work, a marketing team responsible for sales, a promotion team in charge of public relations, and an agency team to liaise for commercials, concerts, and events.

SM Entertainment has also aimed to step into overseas markets based on its unique production system. Since 1998, it has worked to advance into overseas markets such as Japan, Hong Kong, Taiwan, and China with the catchphrase "Culture First, Economy Next." Its entry into overseas markets involves the three strategic stages of cultural export, joint venture, and localization. However, this company is only planning to advance into the third phase, and the concrete 
contents of the strategies and the ways of realizing it will change according to the environmental circumstances. Consequently, it is necessary to confirm how the goals it pursues will be realized in overseas markets.

Therefore, the present study focuses on the exceptional single case of SM Entertainment entering the Chinese market and follows interpretative longitudinal case study procedures (e.g. Hargadon and Douglas) to identify the independent variables necessary to manage the legitimacy. This approach provides a view of the ways in which legitimation strategies of organizations evolve over time for organizational survival.

\section{CHANGES IN CHINESE CULTURAL INDUSTRY POLICY: 1998-2014}

The Chinese government has employed culture as a means of national unification and mobilization through the establishment of a national identity based on the thinking of Mao Zedong. Chinese culture encompasses a strategic tool of the Chinese government for political, economic, and social development. Even after China's reforms and opening, culture has existed as a national governing ideology. Such movements are evident in national slogans such as "construction of socialist spirit civilization" and "construction of socialist culture characterized by Chinese" appearing in relation to culture. As a result, the level of intervention by the Chinese government in the cultural industry is extremely high and its influence and control over cultural industry policy exceptionally strong.

\section{The Emergence of a Cultural Industry: 1998-2002}

Between 1998 and 2002 Chinese laws and regulations related to the cultural industry first emerged. After 1998, the Chinese government turned media companies such as television broadcasting and radio into businesses independent of regular state control. The transition of the newspaper industry followed a similar path. In 2002, the Chinese government began to devote its attention to the development of the cultural industry. At this time, financial support for and legislation of the cultural industry began. During this period, approximately 200 laws and policy documents appeared related to stage arts, newspaper publishing, radio films, and the Internet. These laws include, for example, the Radio \& Television Administrative Laws and Regulations (1997), the Presswork Administration Ordinance (2001), the Film Administration Ordinance (2002), and the Ordinance on Product Management of Sound \& Image Products (2002). 


\section{The Acceptance of Foreign and Private Capital: 2003-2012}

From 2003 to 2012, the Chinese government began to accept foreign and private capital with the goal of developing the national economy through the cultural industry. In 2005, through the "11th Five-Year Plan for Cultural Construction" important basic policies were drawn up to attract Chinese cultural industry development for the subsequent five years. In addition, the degree of acceptance of foreign capital in the cultural industry was selected through the decision on "NonPublic Capital Entry into the Cultural Industry" and "Opinion on Absorption of Foreign Capital in the Cultural Domain." Chinese local governments also established region-specific foreign and private investment policies. For example, Beijing adopted its "Beijing Foreign Investment Policy Regulations." Moreover, in 2011, in order to realize national economic development through the cultural industry, the "Five-Year National Economy Plan" stressed the promotion of foreign capital and private capital in the cultural sphere and the expansion of the government's financial support. As these policies evolved, the examination system for foreign capital was simplified. In the past, the Chinese Ministry of Commerce and the Ministry of Culture strictly controlled the examination of foreign and private capital. In this process, the screening process of foreign and private capital was too complicated and time-consuming. The Chinese government therefore entrusted local governments with screening and filtering authority in order to reduce the administrative process, and local governments minimized the administrative procedures for foreign investment by moderately reducing the review stages.

\section{Network Formation within the Cultural Industry: 2013-2014}

During this period from 2013 to 2014, the Chinese government set three goals for the development of the cultural industry: to utilize actively domestic and overseas market resources, to diversify cultural industry players, and to enhance international competitiveness. To this end, the policies of this period emphasized the importance of Internet companies in the cultural industry with the convergence of the cultural industry and science technology. In this period, the Chinese government focused on researching and developing new technologies related to the content and culture industry. Through the "Cultural Industry Promotion and Development Prosperity of Financial Support," cultural enterprises received an enormous amount of financial support, and the connections between financial capital, social capital, and cultural capital increased. Because of this atmosphere, from 2014 many corporations in China were encouraged to fuse with Internet companies to create higher content value and better product distribution. Within the cultural industry, the development of information technologies (IT) as an 
emerging culture industry was possible, leading to the expansion of distribution and sales networks through the support of mergers and acquisitions. At this time, large Chinese companies such as Baidu, Alibaba, Tencent, and Wanda started to take on mergers and investments in the cultural industry. A blending of the cultural industry and the Internet began in earnest.

\section{THE CHANGE OF LEGITIMATION STRATEGIES: ACQUIESCENCE, COMPROMISE, AND MANIPULATION}

Acquiescence: 1998-2002

During this period, SM Entertainment's exploration of the foreign market environment focused primarily on music concerts in order to simply browse and get a feel for the market. A willingness to develop the cultural industry within Chinese society did not occur until 200o. In the policy, there was no distinction among cultural industries such as entertainment, animation, and media. No governmental policies covered the culture industry, and the establishment of overseas enterprises and business activities of foreign companies were strictly banned in China. At this time, foreign entertainment companies only delivered music performances and recorded music through a Chinese record company. SM Entertainment focused on enhancing its market search ability and intimacy through concert activities, rather than proactively adopting a strategy.

Having earned social recognition through an album by the group HOT, SM Entertainment held a HOT solo concert in Beijing in 2000. The concert met an enthusiastic reception in China and the word "Hallyu" first appeared in Chinese media. In 2001, SM Entertainment put on another concert in Beijing and Shanghai. This concert was an attempt by SM Entertainment to promote singers other than HOT in the Chinese market. In 2002, a larger-scale concert, called "SM Entertainment Live in China," was held at a 15,00o-seat sports center in Hangzhou, Zhejiang Province.

These actions allowed SM Entertainment to build familiarity and awareness in Chinese society. The representative example of this result is that SM Entertainment's singers appeared as the only foreign singers in the "SARS Fighting Concert in China" to commemorate the eradication of SARS, the disease which has wreaked havoc in China in 2003. 


\section{Compromise: 2003-2012}

In 2004, the Chinese government began to allow the use of foreign capital and private capital as well as national capital for the development of the cultural industry. At that point, foreign capital was also permitted entry into the entertainment industry. However, it was only possible to enter the Chinese market through a joint venture with Chinese capital. SM Entertainment quickly responded to the new regulations, establishing in Beijing its joint venture "SMAC," which included SM Entertainment, Chinese Entertainment Chengtian and Japanese company AVEX. The joint venture allowed these three companies to share the creativity and know-how of artist management, music production, and music license sales, while building an entertainment platform in China. While the original objective behind these activities of SM Entertainment was to work within the laws and regulations of the Chinese cultural industry, the company's ability to cultivate its singer and content production technology was enhanced through its broadened resources with the joint venture system. Despite the requirement to follow Chinese cultural industry policy, SM Entertainment was able to establish and utilize resources to localize idol members through the establishment of a platform in China.

From 2005, as the localization strategy to recruit Chinese pop idols began in earnest, boy band Super Junior recruited Chinese members and released Chineselanguage songs. In 2006, SM Entertainment even debuted the Chinese singer Zhang Li Yin, whose performances and songs were sold in Korea, China, and Thailand, and whose first album sold 870,00o copies. With Zhang Li Yin's popularity spreading in China, TVXQ's Xia Junsu and SHINee member Kim Jong-Hyun joined up with the artist to sing in Chinese and raise awareness of Korean singers among Chinese fans. This strategy for intimacy formation through Chinese members led to the idol group $\mathrm{f}(\mathrm{x})$, and the unit groups Super Junior-M and EXO-M.

\section{Manipulation: 2013-2014}

From 2013 to 2014, SM Entertainment expanded its social support through Internet platforms. This strategy was realizable because of the Chinese government's implementation of various policies for development financial instruments and science technology, such as the "Fusion of Culture and Science Technology", the "Intensification of Cultural and Financial Convergence," and "Opinions on Foreign Trade Promotion." Such policies were the outcome of the government's willingness to develop the cultural industry. From this point on, network formation and collaboration among companies in cultural industry began. At this time, China massively increased its support of Internet companies, and Baidu, Weibo, Youku, 
and Alibaba became large corporations. SM Entertainment, eager not to miss out on this opportunity, attempted to network with these online companies.

In 2014, SM Entertainment signed a memorandum of understanding (MOU) with Baidu, China's largest portal site for news, music, and video services, and the distribution of online services. SM Entertainment entered into a strategic alliance with Baidu to distribute online services such as its proprietary music recordings and music videos, and Baidu cooperated with artists in SM Entertainment to coproduce broadcast programs. This allowed SM Entertainment to provide their content online and attract more loyal fans within the so-called SM Town community. For example, SM Entertainment communicates with Chinese fans through Tieba, the primary Chinese online community created and managed by Baidu not only for overseas artists but also for Chinese artists. Chinese fans visit Tieba over 90 million times a month to communicate with EXO. SM Entertainment also set up an official SM Town page on Weibo. As of February 2017, the number of fans on SM Town's official page stood at 1,101,433.

This movement by SM Entertainment through the Chinese online system shows a more active attitude toward Chinese cultural industry policies than the company's previous strategies. SM Entertainment actively employed such policies to network with Internet media. It adopted social media as a resource, focusing not only on its connection with foreign capital, but also implementing various localization strategies as an active response to communicate with Chinese fans. SM Entertainment's most basic form of localization strategy was to recruit Chinese members in its idol groups, whereby the company focused on localizing the cultural content itself. Localization through social media was not a passive approach, as it not only changed content but also changed discourse in Chinese society involving communication with people in the country. 
Table 1. Changes in Legitimation Strategies, 1998-2014

\begin{tabular}{|c|c|c|c|}
\hline & Cultural Industry Policy & Active & Legitimation Strategy \\
\hline 1998 & \multirow{5}{*}{$\begin{array}{l}\text { The Emergence of } \\
\text { Cultural Industry }\end{array}$} & Salec HOT music recordings & \multirow{5}{*}{$\begin{array}{l}\text { 'Acquiescence': } \\
\text { passive strategy }\end{array}$} \\
\hline 1999 & & 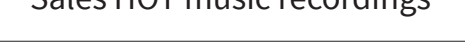 & \\
\hline 2000 & & HOT Concert & \\
\hline 2001 & & \multirow{2}{*}{ SM Town Live in China } & \\
\hline 2002 & & & \\
\hline 2003 & \multirow{10}{*}{$\begin{array}{c}\text { The Acceptance of } \\
\text { Foreign and Private } \\
\text { Capital }\end{array}$} & - & - \\
\hline 2004 & & Established a Chinese branch & \multirow{9}{*}{$\begin{array}{l}\text { 'Compromise': } \\
\text { conformity and use local } \\
\text { resources }\end{array}$} \\
\hline 2005 & & $\begin{array}{l}\text { Recruited Chinese members at } \\
\text { Super Junior }\end{array}$ & \\
\hline 2006 & & Zhang Li Yin debut & \\
\hline 2007 & & $\begin{array}{l}\text { Established joint venture with } \\
\text { AVEX and Chengtian }\end{array}$ & \\
\hline 2008 & & $\begin{array}{l}\text { Commitment of Chinese } \\
\text { member to Super Junior-M }\end{array}$ & \\
\hline 2009 & & $\begin{array}{c}\text { Commitment of Chinese } \\
\text { member to } f(x)\end{array}$ & \\
\hline 2010 & & - & \\
\hline 2011 & & - & \\
\hline 2012 & & $\begin{array}{c}\text { Made unit group EXO-M which } \\
\text { is composed of only Chinese } \\
\text { members }\end{array}$ & \\
\hline 2013 & \multirow[b]{2}{*}{$\begin{array}{c}\text { Network Formation } \\
\text { within Cultural Industry }\end{array}$} & \multirow[b]{2}{*}{$\begin{array}{l}\text { MOU with Chinese online } \\
\text { companies }\end{array}$} & \multirow{2}{*}{$\begin{array}{l}\text { 'Manipulation': } \\
\text { capture and value } \\
\text { diffusion }\end{array}$} \\
\hline 2014 & & & \\
\hline
\end{tabular}

In sum, SM Entertainment developed a three-staged strategy in China in response to the changes of Chinese cultural industry policy (see Table 1). First, since there were few policies and regulations on the cultural industry in the early stage of the development of the Chinese culture industry, SM Entertainment pioneered the market through its singers' music concerts. Second, as the reform of the Chinese cultural industry progressed, foreign investment was allowed for the first time and concrete cultural industrial policies began. SM Entertainment reacted by establishing a Chinese branch and a joint venture with a corporation in China, effectuating a localization strategy. Some might point out that the formation of the SMAC joint venture, which is the first part of compromise, falls under the category of an acquiescence strategy. However, this is not the nature of acquiescence. In fact, the acquiescence stage does not mean utilizing or changing the existing order, but rather complying with the content and conditions of the rules. However, the formation of a joint venture through this utilization of policies has facilitated the recruitment of Chinese pop idols. 
Third, from 2013, Chinese cultural industry policies became more specific and increased the degree of cultural industry development through convergence with the financial industry and science technology. Under such a policy environment, SM Entertainment formed a strategic alliance with large-scale Chinese enterprises and executed MOUs with Chinese online companies.

\section{The Results of Legitimation Strategies}

SM Entertainment has faced internal obstacles such as local Chinese singers' contract disputes and withdrawal from the company, and external obstacles such as the intervention of and sanctions by the Chinese government, and political issues between countries. However, as we have shown in this paper, the corporation has mitigated these obstacles and pressures through legitimation strategies. SM Entertainment initially entered China through music concerts. Over time, however, the company has implemented a strategy to distribute revenue by collaborating with Chinese corporations to distribute profits, use contents platform, and communicate via social media through partnerships with Internet companies. As SM Entertainment has diversified its available resources by implementing various strategies and tactics beyond mere music contents exports, it has enhanced its chances to survive and to increase revenues. According to SM Entertainment's business report, the company's revenues in 2014 reached 280 billion won, a $6.8 \%$ increase over 2013.

In addition to this increase in sales, the number and popularity of SM Entertainment singers in China has surged. Youku, a website similar to YouTube, is the most influential online video site in China. In this video platform, SM Entertainment has created an SM Town channel to communicate with Chinese fans. By 2014, the number of fans was 51,367 people and the total number of music video views was $61,195,710$. Among them, the highest number of music video views by 2014 was "Mr. Mr." by Girls' Generation, which recorded 3,299,267 hits, "Growl" by EXO, with 2,882,534 hits, and "Pathcode" by Lay in EXO, with 2,759,221 hits.

SM Entertainment's musical artists in China are not only more popular than singers from any other foreign country but also surpass the popularity of Chinese singers, despite coming from Korea. Currently, the most popular top Chinese idol singer, Zhang Liangying, has 32,630,ooo fans, and Zhou Bi Chang has 17,720,00o fans. These Chinese singers have participated not only in performances but also in dramas and movies. On the other hand, Korean singers have relatively few activities in China and appear in only a few dramas or movies, but have scores of Chinese fans. EXO-M, which debuted in 2011, gained 3,630,00o fans in just four years. They 
have three times the number of fans of Phoenix Legend (1,210,0oo fans) a popular Chinese duo with a near-decade history. There are 13,912,220 fans of Siwon Choi and 2,238,305 fans of Hee chul Kim (both Super Junior members), a number similar to top-ranking Chinese singers.

SM Entertainment has also been acclaimed musically with a continuous stream of awards in China. The company has received the most music prizes among overseas entertainment companies in China. The Top Chinese Music Awards selects the most popular singers every year, with decisions made via Internet-based fan votes, and overseas groups in China as well as Chinese groups are eligible for these awards. In 2013, EXO-M was selected as the most popular group in China. In 2014, Super Junior's music video "Break Down" was selected as the best music video. And EXO-M is the first award-winning Korean idol group.

The degree of broadcasting activity of a singer shows whether social support has been secured from Chinese society. This is because broadcasting activities can only be achieved through social demand and favorable reception. In the early days, when SM Entertainment's singers entered the Chinese market, they mainly focused on performances. However, since 2013, their singers have been active on Chinese TV talk show programs. SM Entertainment singers have already appeared on Hunan Broadcasting System's "Happy Camp" three times, and have been invited to participate in the "Happy Camp 15th Anniversary Special Program." "Happy Camp" is the most popular talk show program in China and the guests of that program are usually the most popular actors and singers in China. To be invited to the program's fifteenth anniversary feature and appear on its radio shows means that SM Entertainment's singers are popular and socially supported in China.

The increase in the number of concert audience attendees also shows the degree of social support of SM Entertainment. In 2009, "Super Junior the First Asia Tour in Nanjing" concert was performed to a crowd of 20,000 people. In September 2010, "SM Entertainment's Live Concert in Shanghai" had 25,0oo viewers, and in October 2014 the concert attracted 30,000 spectators. The number of people who want to buy SM Entertainment concert ticket is increasing steadily; in October 2013, the 'SM Town Live World Tour' in Beijing had 70,0oo spectators.

\section{CONCLUSION}

This study confirms that SM Entertainment has developed in the Chinese market along with the development of the Chinese cultural industry. As the company responded to changes in Chinese cultural industry policy, we confirmed that there 
was a certain pattern of change in the strategies of SM Entertainment due to changes in Chinese cultural industry policy over time. SM Entertainment's strategies have not only included passive adaptation but have also shown an active response to the changes of cultural industry policy as external environments. Through these responses, SM Entertainment has survived in the Chinese market.

This analysis sheds light on two important points that are normally overlooked in Hallyu studies, in regards to the institutional adaptation process of Korean Entertainment companies of Hallyu products overseas. First, there are legitimation strategies to secure social support for organizations. Above all, the Hallyu phenomena denote the processes in which an external existence spreads to other social systems and settles. To analyze Hallyu phenomena, the possibility of conflict between different institutional frames should be considered. Meanwhile, the alleviation of this conflict can be socially supported. Of course, it is difficult for actors to escape the pressure of social order composed of rules, norms, judgments, and social expectations. However, actors are not just "puppets programmed with culturally determined scripts" (Aldrich 339).

Second, these legitimation strategies can change over time. This is because companies have implemented strategies to obtain social support in accordance with the characteristics of the changing external environment, and the types of resources available to the organization. Through a longitudinal study of SM Entertainment in the Chinese market, we identified acclimatization strategies and the evolution of legitimation strategies. Legitimation strategies do not happen discontinuously but are rather an accumulated repertoire. This means that over time the strategic resources that organizations can utilize simultaneously increase. Since SM Entertainment was adapting to a change of environment, they had the ability to make use of strategies other than conformity, including the simultaneous use of conformity, comprise, and manipulation. As a result, SM Entertainment, unlike AVEX Entertainment, was able to survive in an unpredictable and changeable Chinese market.

There is an old Chinese saying: "If the climate and nature differ, when a mandarin orange planted south of the river is transferred to the north of the river, it becomes a tangerine." The metaphor is a reminder that people change depending on their surrounding environment. Companies that enter overseas markets will also face a process of adaptation to new external environments. The cultural industry policy in China is an external environment, and SM Entertainment, as a cultural production organization, had to consider and accept it for survival. 


\section{Notes}

1. This work was supported by the Ministry of Education of the Republic of Korea and the National Research Foundation of Korea (NRF-2015S1A5B6036421).

2. Legitimacy is defined as "a generalized perception or an assumption that the actions of an entity are desirable, proper, or appropriate within some socially constructed system of norms, values, beliefs and definitions" (Suchman 573).

3. SM Entertainment started in 1989 as SM Agency, but the business failed when it debuted a group called "Jin-Young Hyun and Wawa" because of Jin-Young Hyun's illegal use of marijuana. From this moment on, the CEO Soo man Lee perceived the necessity of fostering a system of entertainers. On April 8, 2009, Lee gave a lecture at Seoul National University under the theme "Global Strategy: Challenges and Planning of the Korean Culture Industry." In the lecture, he said improvements were needed in music distribution structure and that a systematic program of education was required to develop entertainers after the incident with Jin-Young Hyun.

4. The change of Chinese cultural policies cited in this study is taken from the author's A Study of the Relationship between the Changing Chinese Cultural Industry Policy and Entertainment Company's Strategic Choices (MA thesis. Korea University, 2015). 


\section{Works Cited}

Aldrich, E. Howard. "Beam Me Up, Scott(ie)! Institutional Theorists' Struggles with the Emergent Nature of Entrepreneurship." Research in the Sociology of Work, vol. 21, 2010, pp. 329-364.

Cho, Byung-Chul and Hichul Sim. "Success Factor Analysis of K-POP and a Study on Sustainable Korean Wave: Focus on Smart Media Based on Realistic Contents K-POP." (K-POP 한류의 성공요인분석과 한류 지속화 방안연구: 스마트 미디어 기반 실감콘텐츠 활용을 중심으로). International Journal of Contents, vol. 13, no. 5, 2013, pp. 90-102.

Cui, Geng, and Qiming Liu. "Regional Market Segments of China: Opportunities and Barriers in a Big Emerging Market." Journal of Consumer Marketing, vol. 17, no. 1, 2000, pp. 55-72.

Deephouse, David L. and Mark Suchman. "Legitimacy in Organizational Institutionalism." The Sage Handbook of Organizational Institutionalism, edited by Royston Greenwood, Christine Oliver, Kerstin Sahlin, and Roy Suddaby, Sage, 2008, pp. 49-77.

Dess, Gregory G., and Donald W. Beard. "Dimensions of Organizational Task Environments." Administrative Science Quarterly, vol. 29, no. 1, 1984, pp. 52-73.

DiMaggio, Paul and Walter W. Powell. "The Iron Cage Revisited: Collective Rationality and Institutional Isomorphism in Organizational Fields." American Sociological Review, vol. 48, no. 2, 1983, pp. 147-160.

Greenwood, Royston and Christopher R. Hinings. "Understanding Radical Organizational Change: Bringing Together the Old and the New Institutionalism." Academy of Management Review, vol. 21, no. 4, 1996, pp. 1022-1054.

Hargadon, Andrew B. and Yellowlees Douglas. "When Innovations Meet Institutions: Edison and the Design of the Electric Light." Administrative Science Quarterly, vol. 46, no. 3, 2001, pp. 476-501.

Jang, Gyu-Soo. "Overseas Advance Instance and Strategic Study of Korean Pop Music." (한국 대중음악의 해외진출 사례와 전략 연구). The Journal of Global Cultural Contents 2, 2009, pp. 217-238.

Khanna, Tarun and Krishna Palepu. "Why Focused Strategies May Be Wrong for Emerging Markets." Harvard Business Review, vol. 75, no. 4, 1997, pp. 41-48.

Kim, Myoungsoo. "Manufacturing 'Hallyu': A Historical Institutional Analysis." ('한류' 제조하기: 역사제도주의적 해석). Korean Journal of Sociology, vol. 49, no. 2, 2015, pp. 35-65.

Kim, Ju-Yeon and Kyung-Mo Ahn. "How Chinese Population's Preference to Korean Wave Contents Does Influence their Intent to Purchase Korean Product, Visit Korea, and Learn Hangul." (중국에서의 한류콘텐츠 선호가 한국상품 구매, 한국방문 및 한글학습의도에 미치는 영향). International Journal of Contents, vol. 12, no. 5, 2012, pp. 447-458.

Kim, Young-Ah. "Research of the Change in Korean Popular Music after the 1990s: Based on SM Entertainments and JYP Entertainments." (1990년대 이후 한국 대중음악계의 
변화에 관한 연구: SM 엔터테인먼트와 JYP 엔터테인먼트를 중심으로). Humanities Contents 12, 2008, pp. 159-175.

Kostova, Tatiana, Kendall Roth, and M. Tina Dacin. "Institutional Theory in the Study of Multinational Corporations: A Critique and New Directions." Academy of Management Review, vol. 33, no. 4, 2008, pp. 994-1006.

Lee, Moon Haeng "Penetration Strategies of SM Entertainment in Global Market." (SM 엔터테인먼트의 글로벌 시장 진출 특성). Journal of Information Technology Services, vol. 13, no. 3, 2014, pp. 77-92.

Lee, Jang Hyuk, Ka Yoon Kim, and Won Seok Woo. "Impact of K-POP on Export: Based on YouTube Page View and Google Search.” (K-POP이 수출에 미치는 영향: YouTube 조회수와 Google 검색을 중심으로). Journal of Marketing Management Research, vol. 19, no. 4, 2014, pp. 83-97.

Li, Jiatao and Rajiv Krishnan Kozhikode. "Knowledge Management and Innovation Strategy: The Challenge for Latecomers in Emerging Economies." Asia Pacific Journal of Management, vol. 25, no. 3, 2008, pp. 429-450.

Meyer, John W. and Brian Rowan. "Institutionalized Organizations: Formal Structure as Myth and Ceremony." American Journal of Sociology, vol. 83, no. 2, 1977, pp. 340-363.

Miller, Danny and Peter H. Friesen. "A Longitudinal Study of the Corporate Life Cycle." Management Science, vol. 30, no. 10, 1984, pp. 1161-1183.

Oetzel, Jennifer, Kathleen A. Getz, and Stephen Ladek. "The Role of Multinational Enterprises in Responding to Violent Conflict: A Conceptual Model and Framework for Research." American Business Law Journal, vol. 44, no. 2, 2007, pp. 331-358.

Oliver, Christine. "Strategic Responses to Institutional Processes." Academy of Management Review, vol. 16, no. 1, 1991, pp. 145-179.

Oh, Ingyu, and Gil-Sung Park. "From $\mathrm{B}_{2} \mathrm{C}$ to $\mathrm{B}_{2} \mathrm{~B}$ : Selling Korean Pop Music in the Age of New Social Media." Korea Observer, vol. 43, no. 3, 2012, pp. 365-397.

Park, Gil-Sung. "Manufacturing Creativity: Production, Performance, and Dissemination of K-pop." Korea Journal, vol. 53, no. 4, 2013, pp. 14-33.

Park, Young Eun and Dong Kee Rhee. "SM Entertainment, Race for the Global Entertainment." (SM 엔터테인먼트, 글로벌 엔터테인먼트를 향한 질주). Korea Business Review, vol. 15, no. 2, 2011, pp. 65-99.

Peng, Mike W., Sunny L. Sun, Brian Pinkham, and Hao Chen. "The Institution-based View as a Third Leg for a Strategy Tripod." The Academy of Management Perspectives, vol. 23, no. 3, 2009, pp. 63-81.

Pfeffer, Jeffrey and Gerald R. Salancik. The External Control of Organizations: A Resource Dependence Approach. Harper and Row, 1978.

Ramamurti, Ravi and Jitendra V. Singh. "Indian Multinationals: Generic Internationalization Strategies." Emerging Multinationals in Emerging Markets, edited by Ravi Ramamurti and Jitendra V. Singh, Cambridge UP, 2009, pp. 110-167.

Suchman, Mark. "Managing Legitimacy: Strategic and Institutional Approaches." Academy of Management Review, vol. 20, no. 3, 1995, pp. 571-610.

The State Council, The People's Republic of China. http://www.gov.cn. Accessed 29 Dec. 2014. 
Tolbert, Pamela S., and Lynne G. Zucker. "Institutional Sources of Change in the Formal Structure of Organizations: The Diffusion of Civil Service Reform, 1880-1935." Administrative Science Quarterly, vol. 28, no. 1, 1983, pp. 22-39.

Walsh, John. 2014. "Hallyu as a Government Construct: The Korean Wave in the Context of Economic and Social Development." The Korean Wave: Korean Popular Culture in the Global Context, edited by Yasue Kuwaahara, Palgrave Macmillan, 2014, pp. 13-22.

Won, Yong-Jin. "Hallyu Policy and Soft Nationalism." (한류정책과 연성국가주의). Kwanhun Journal 123, 2012, pp. 46-52.

Ye, Weibo. A Study of the Relationship between the Changing Chinese Cultural Industry Policy and Entertainment Company's Strategic Choices: Based on SM Entertainment. ( 중국의 문화산업정책과 기획사의 전략변화 연구: SM 엔터테인먼트를 중심으로). MA Thesis. Korea University, 2015.

Zald, Mayer N. and Patricia Denton. "From Evangelism to General Service: The Transformation of the YMCA." Administrative Science Quarterly, vol. 8, no. 2, 1963, pp. 214-234. 